\section{Which way to organizational excellence? Not this way; ask a professional}

History suggests that regulatory bodies, like the Healthcare Commission in England, do not usually impose standards to achieve excellence in health care. A 'hospital standardization program' started in 1917 when the American College of Surgeons published standards for recognizing ('accrediting') suitable posts for trainees. The idea evolved into national, voluntary accreditation of whole hospitals in the USA, Canada and Australia, led in each case by associations of doctors, nurses and administrators. Uptake was rapid and extensive across the country because accreditation brought financial benefits from private and public agencies, and because state and provincial governments were willing to reciprocate rather than compete.

Europe has been slow to codify standards for health services. Here, similar 'collegial' programmes failed to thrive in the 1990s, largely from lack of financial incentives to participate. ${ }^{1}$ But a new model is emerging of national bodies which use combinations of organizational standards, clinical indicators and evidence-based guidelines for assessment and accreditation of health care providers. Agencies in France, Scotland, Denmark, The Netherlands and Ireland have some elements in common with the Healthcare Commission as assessors of healthcare standards. However, they are also essentially different in that they are governed largely by clinicians and managers, they develop their own standards together with professions and end users, and their staff are recruited from the health services which they assess. And the government-supported programmes in France and Ireland have submitted their standards and assessment procedures for independent international scrutiny.

There is little to explain why England and Wales should be so different from their neighbours, and few signs that Standards for Better Health ${ }^{2}$ will lead to organizational excellence. The first annual health-check by the Healthcare Commission $^{3}$ tells us that just half of the 570 NHS trusts in England comply with all the 'core' standards which the Department of Health assumed had been met two years ago. 4

These findings reinforce concerns that the core standards were built on false assumptions and have not been well tested before being put into judgmental use. ${ }^{5}$ Ten to twenty percent of trusts do not comply with mandatory requirements concerning medical devices, sterilization, records management, staff training and evidence-based clinical practice. The Commission penalized trusts whose self-assessments were deemed inflated, implying that the discrepancies were due to wilful gaming rather than any weakness of the standards or of the assessment processes which had not previously been tested. And now that the compliance gaps are published, can we assume they will be self-closing?

The Commission has done well to craft a semi-silken purse out of the core standards, but much work will have to go into basic systems before some trusts, or the Commission, are ready for the second barrel of the Standards for Better Health, the much more demanding 'developmental' standards. 'Shadow assessments' of three of the seven domains of these standards will be introduced in the 2006-2007 health check in England; the Health Inspectorate Wales is currently consulting on assessment procedures against similar standards. ${ }^{6}$

The problem is that the behavioural dynamics and technical mechanisms of regulatory inspection and of organizational development are quite different. Inspection wastes little time on evidence, consultation, user participation or methodology, and all standards are equally mandatory. Developmental standards need the credibility of robust development, ownership by the people and organizations that will use them, and reliable methods of assessment, differential scoring, grading and appeals. And they need time.

The Commission was set up as an inspectorate at arm's length from managers and clinicians, and thumb's length from government. The standards (core and developmental) were drafted by the Department of Health with little technical rigour or input from staff at the front line, and are to be applied by a Commission which has little first-hand experience of the services it is expected to help develop. The Commission is the largest healthcare regulator in Europe even before it merges with the Commission for Social Care and Inspection-or starts assessing developmental standards - but it does not have the chemistry to ignite a commitment to excellence within trusts. Unlike basic standards, optimal standards and best practice must win hearts and minds of health care staff and be driven from within.

This drive for development will not come from stitching professional bodies into a concordat with regulatory bodies. Across the UK, an epidemic of public inquiries has urged accountability and professional self-governance at local level but effectively reduced the influence of professional bodies and associations at national level. These are the very bodies most likely to succeed with developmental standards, and many have already refined peer review programmes; sadly, most of these have little funding, limited voluntary uptake and direct competition from mandatory regulators. Together with other users and providers of health care, the professions have experience and insight into the 
behaviour of practitioners, and the flexibility to work across political borders and contribute to standards of training, service delivery and clinical practice across the UK and within Europe.

A glimpse around the world commends a model for standards-based assessment and development which:

- Aims for excellence for internal customers (such as staff), as well as external ones (such as patients);

- Is governed by a balanced representation of stakeholders (including but not dominated by regulators);

- Leads to financial, training or recruitment advantage for recognized organizations;

- Generates sufficient income from services to fund core operations;

- Integrates improvements in institutional organization, clinical practice and professional development;

- Combines self-assessment with external peer review;

- Is compatible with neighbouring countries (e.g. enables cross-border flow of patients, services and staff, and implements guidance and directives of the European Union); and

- Complies with international expectations of standardsbased assessment programmes. ${ }^{7}$

Each government has responsibility for stewardship of the health system, both public and private, within its own borders; but the UK, and particularly England, is abnormally resistant to sharing this with providers and professions. The Healthcare Commission is the latest watchdog in England to offer assurance through inspection of basic safety and 'core standards', and has built on the experience of the Commission for Health Improvement, ${ }^{8}$ its predecessor, to add the surveillance of performance using intelligent data and measurement systems. But developmental standards are more about changing the behaviour of organizations and individuals than about measuring; organizational excellence demands a different approach to motivation, learning and clinical systems.

That is not the expertise of the Commission, but of professional associations, educators and other providers. Some medical colleges (notably the Pathologists,
Psychiatrists and General Practitioners) have already developed models of standards-based peer review which could contribute to a practical national model. But the factions of professions and providers would have to be able and willing to work together, to suppress tribal instincts for independence, and to converge on the common cause of excellence in health care. That would also demand a new discipline of scientific rigour in defining, measuring and improving standards (both clinical and organizational), more transparent procedures, and more sharing of results with legitimate stakeholders, including the public. And that would need a body such as the Academy of Medical Royal Colleges to be a key partner, if not the leader of standards for excellence.

Competing interests None declared.

\section{Charles D Shaw}

Roedean House, Brighton BN2 5RQ

E-mail: cdshaw@btopenworld.com

\section{REFERENCES}

1 Shaw CD. Accreditation in European Healthcare. Joint Commission Journal on Quality and Patient Safety 2006;32:266-75

2 Department of Health. National Standards, Local Action. Health and Social Care Standards and Planning Framework 2005/06-2007/08. Annex 1. Leeds: DoH, 2004. Available at www.dh.gov.uk/publications

3 Healthcare Commission. Results of the Annual Health Check 2005/2006. London: Healthcare Commission, 2006. Available at http:// annualhealthcheckratings. healthcarecommission.org.uk

4 DoH. Standards for Better Health. para 20. 'Meeting the core standards is not optional. Health care organisations must comply with them from the date of publication of this document.' London: DoH, 2004

5 Shaw CD. Standards for better health: fit for purpose? BMJ 2004;329:1250-1

6 Healthcare Standards for Wales. Making the Connections Designed for Life. Cardiff: Welsh Assembly, 2005. Available at http://www.hiw.org.uk/ page. . fm?orgid $=477$ \&pid $=15775$

7 International Society for Quality in Healthcare. International Accreditation Standards for Healthcare External Evaluation Bodies. Second Edition. Melbourne: ISQH, 2004. Available at http://www.isqua.org/ isquaPages/Accreditation/ISQuaSurvStandards2.pdf

8 Attride-Stirling J, Humphrey C, Tennison B, Cornwell J. Gathering data for health care regulation: learning from experience in England and Wales. J Health Serv Res Policy 2006;11:202-10 